20. Man, No. 6773 , aged 59, married, 22-v17. Hypertrophy of prostate. The usual perineal prostatectomy. Complications: Epididymitis lasting from the fifth to the twelfth day after operation. The patient was discharged one month after operation. Result: 14-vii-17. The wound has healed. Patient has no difficulty in urination, but the left epididy. mis is still painful.

21. Man, No. 5322, aged 51, married, 31viii-16. Hypertrophy of prostate. Tabes. Perineal prostatectomy. Moderate enlargement of lateral lobes; none of median. There were no complications. The wound healed on the eleventh day. The patient was discharged on the sixteenth day after operation. Result: 2vii-18. Patient in excellent condition. No straining. Rises once at night to urinate. Erections still active. Has been treated for syphilis by his physician with good results. Still carries a small residual urine.

22. Man, No. 7202. aged 77, 12-viii-17. Hy. pertrophy of prostate. Perineal prostatectomy. Usual perineal approach; one portion of a lateral lobe impossible to reach, so that a suprapubic opening was made. Anesthesia stormy. Complications: Patient had an attack of auricular flutter on the fifth day after operation, controlled by digitalis. He was discharged on the thirty-eighth day after operation. vii-18. A perfect result: Urine clear; no residual; no frequency.

23. Man, No. 6807, aged 65, 30-v-17. Hypertrophy of prostate. Perineal prostatectomy. Median lohe removed through right cavity Some fever for eighteen days. Sinus not healed on discharge on thirty-fifth day after operation. Reëntry: S-x-17. Urethro-rectal fistula. Repair of fistula: suprapubic drainage of bladder. Hard dissection through dense scar tissue. Impossible to bring opening into rectum entirely outside sphincter. No complications. Discharged thirty days after operation. Result: 26. vii-1S. Symptomatically well. Urine turbid, for which had argyrol instilled once a week. 9-iv-19. Fistula is entirely healed and patient considers himself well in all respects. General health is much improved and patient is working every day with regularity. The urine is slightly turbid.

24. Man, No. 6124, aged 54, 22-i-17. Hypertrophy of prostate. Perineal prostatectomy. Fnlargement of small degree, most of difficulty being due to contraction of neck of bladder. No complications. Patient was discharged twenty-seven days after operation. Reëntry: 28-v-17. Since operation has had a small sinus in perineum which has leaked a few drops of urine once: or twice each week. Excision of perineal sinus. Urethra dissected free from scar tissue and drained by in-lying catheter. No complications. Patient was discharged on ninetecnth day after operation. Result: 16 vii-18. Still has occasional leakage from perineum. Inlting or enughing causes slight incontinence. General condition excellent. ix18. Sinus through which urine and pus discharge still remains. Urine cloudy with a few shreds. 22-iii-19. Perineal sinus continues to discharge one or two drops of urine occasionally. Urine slightly turbid.

(To be continued.)

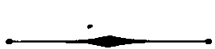

\section{Uliniral Bppartment.}

\section{FAT TRANSPLANTATION AFTER EX- CISION OF CICATRICIAL CONTRAC TION OF LOWER JAW, WITH REPORT OF A CASE.}

\section{By Wiltitam Reid Morrison, M.D., Boston.}

Surgical reconstruction of the face has received a great impetus, because of the interest aroused in this subject, not only resulting from industrial accidents, but also from war wounds. Injury to the soft tissues may cause a most disfiguring scar, particularly if any necrosis occurs, and the wound becomes infected. The cicatrix itself is usually depressed below the surface of the surrounding skin, causing elevated areas which simulate ulceration of the teeth. The patient is constantly annoyed by questions of solicitous friends as to the cause of the swelling.

Following severe crushing injuries, not only the skin, but the subcutaneous fat, fascia, and muscles may slough, involving the adjacent blood vessels, lymphaties, motor and sensory nerves, with subsequent partial facial paralysis and loss of sensation.

Loss of function of the jaws due to cicatricial contractions is a serious complication, for the patient may be unable to eat any solid food. The average adult cannot work efficiently on a liquid diet only.

Salivary fistulae may develop from injury of Stenson's duct, or the parotid or submaxillary glands, which are to be avoided by the surgeon. Simple or compound fractures may be found involving the antrum of Highmore, or the frontal sinuses, sometimes opening into the buccal cavity or nasal passages.

After excising the scar in the skin, and undermining the surrounding skin as much as necessary, avoiding important structures, the cicatricial tissue may be severed, with a finger 
in the buccal cavity as a guide. A layer of subcutaneous fat may then be transplanted from the thigh or abdomen, placing the transplant between the adjacent edges of the severed scar tissue, and also under the skin, to fill in any depressed areas. Since the tissues of the face are very vascular, all bleeding must be carefully stopped, and great care should be taken not to incise the mucous membrane of the buccal cavity. Strict asepsis is essential for a successful isograft. Intrapharyngeal ether aids the operator greatly, for the ether cone is dispensed with, and the anesthetist is not in the surgeon's way.

The following industrial accident case was recently referred to the writer for operation by Dr. A. L. MeLaren:

J. J. S., twenty-two years of age, single. Family history and past history irrelevant.

Patient stated that on July 10, 1919, he was working at a wharf, pile-driving, and while he was guiding a pile into the proper position with a pole, the pole was struck by the pile-driving hammer weighing about twenty-eight hundred pounds. The pole hit the patient's face, tearing open the right cheek into the buceal cavity. The boy was knocked overboard into the sea-water, and was taken, unconscious, to a pulblic hospital. The record states that there was much necrosis of the soft tissues of the face. and the wound was dressed, its edges being ap. proximated as carefully as possible by the hospital surgeon. The patient was in bed for six days, then was treated in the out-patient clinic. Cicatricial contraction prevented the lower jaw opening, so that the patient could not open his mouth to eat solid food; he could only drink liquid nourishment.

Examination of the case on Septemiber 19, 1919 , at the writer's office was as follows: Patient presented a depressed, semi-lunar scar of the right cheek, midway between the ear and the mouth. The upper end of the scar was at the level of the lower border of the zygomatic process, passing backward and downward eight centimeters to the middle of the ramus of the lower jaw. The skin between the scar and the midline of the face showed impaired sensation, because of fifth nerve injury, and there was also partial motor involvement of this region, for the patient could not whistle, and could only slightly move the right corner of the mouth (damage of the seventh cranial nerve.) The area betweem the scar, and the nose and mouth protruded, simulating a swelling due to an uleerated tooth. Examination of the buceal eavity was negative. The mouth could be opened the distance of one-half of one centimeter between the opposing incisor teeth.
An x-ray plate of the face, and general examination were negative.

A diagnosis was made of cicatricial contraction of the lower jaw, due to scar in the soft tissues of the right cheek. Partial ankylosis of the jaw was considered. Operation was advised and accepted.

On October 3, 1919, the patient entered the Boothby Surgical Hospital. The right face and right thigh were prepared by shaving the skin. soap and water scrub, followed by seventy per cent. alcohol and sterile dressing. The operation was performed on the following day. Nitrous oxide gas and intrapharyngeal ether were given by Dr. Lyman S. Hapgood, Dr. McLaren assisting. Benzine and half-strength tincture of iodine were applied for skin preparation. Morphine sulphate, one-sixth of a grain, and atropine sulphate one hundred and fiftieth of a grain were given subcutaneously one hour before operation. Under ether an attempt was made to open the jaws with a mouth gag, but proved ineffectual.

The cutaneous cicatrix was excised, and the surrounding skin undermined by sharp dissection for a distance of three centimeters. Stenson's duct was separated from the scar tissue and isolated. The masseter muscle was identified, and with a finger in the mouth as a guide, the scar tissue was severed, and the lower jaw mobilized, eare being taken not to incise the buccal mucous membrane and infect the wound. All bleeding points were ligated with iodized catgut number one. The lower jaw could then be opened so that the incisor teeth of both jaws were separated for a distance of four centimeters. A flap of skin ten centimeters long by six centimeters wide, on a pedicle, was dissected from the anterior and outer aspect of the right thigh, and the underlying fat was transplanted between the cut edges of the masseter muscle, to prevent cicatricial contraction, and also beneath the undermined skin, to fill out the right cheek to conform to the contour of the left cheek. These isotransplants were kept moist with warm salt solution. Interrupted subcuticular iodized catgut number one sutures were inserted, with a few horse-hair stitches, in the wound of the face. Silkworm gut sutures were used for the leg wound. Dry sterile dressings were applied.

The lower jaw was opened three times a day subsequently by means of a mouth gag. The wound of the face healed by first intention, and the horse-hair stitches were removed on the sixth day. The patient was discharged from the hospital on the seventh day. The stitehes in the leg were rmoved on the tenth day, therc being some necrosis of the upper edges of the leg wound, which healed ten days later. The patient then could eat a regular diet; the contour of the right cheek was normal, with a linear scar level with the skin. Sensory as 
well as motor nerve involvement was impaired as before operation.

The boy was seen again in December, and had been doing his regular work, having an excellent functional as well as cosmetic result.

\section{A CASE SHOWING APPARENT PARA-} DOXICAI: RESPIRATORY ARRHYTHMIA OF 'TFF HEART'.

\section{By Paul D. White, M.D., Boston,}

\section{Massachusetts General Hospital.}

CASE : W. J. S., 23 years old. Private of Engineers. In Base Hospital No. 6, A. E. F., November 10, 1918, with influenza. Past history: Very severe "double pneumonia" at the age of five, since which time his pulse has always been slow. Patient says that pulse always gets slower on excitement or on exertion-this has been noted for years. Typhoid fever five years ago. - Examination shows patient convalescing from influenza. Heart not remarkable in size or sounds, but rate slow.

The following table shows the auriculo-ventricular rates under different circumstances, as determined lby polygrams taken with the Jaquet polygraph :-

\begin{tabular}{|c|c|}
\hline $\begin{array}{l}\text { AURICULAR } \\
\text { RATE }\end{array}$ & $\begin{array}{l}\text { VENTRICULAR } \\
\text { RATE }\end{array}$ \\
\hline Quiet in bed & 43 \\
\hline Quiet in bed (later) & 40 \\
\hline During deep inspiration 70 & 35 \\
\hline Deep expiration ......44 41 & 41 \\
\hline $\begin{array}{l}\text { Immediately after mod. } \\
\text { erate exertion } \ldots \ldots \ldots \text { i2 }\end{array}$ & 36 \\
\hline
\end{tabular}

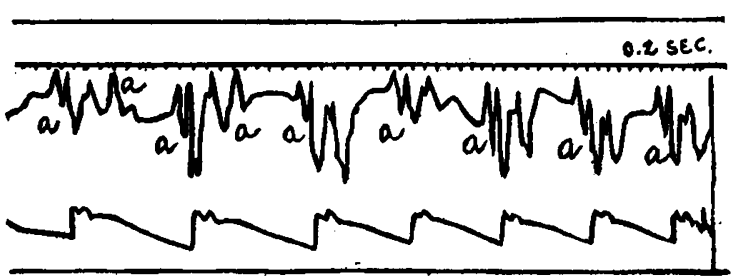

Polygram of W. J. S. Dec. 7, 1918, explaining the apparently paradoxical respiratory arrhythmia of the heart. Jugular pulse tracing above, radial pulse tracing below. Full inspiration at the beginning.

Note that with inspiration the auricular rate $(a-a-a)$ is more rapid and is attended by two to one auriculo-ventricular heart block resulting in a slow ventricular action

Time marker, 0.2 sec.

\section{DISCUSSION.}

Ordinarily one finds an increase in heart rate with inspiration and exercise. In this instance we find a decrease in heart rate with inspiration and exercise. This paradoxical condition is due to the occurrence of 2-to-1 heart block when the auricular rate rises above a certain point (See figure). Evidently the auriculo-ventricular junctional tissue is depressed, probably by disease in early childhood, so that beyond a certain point it fails to transmit every other auricular impulse.
Actually, the pacemaker of the heart does respond normally to respiratory influence and exertion, but the block produces this unusual finding of slowing during inspiration and exertion. During the slow rate the auriculo-ventricular conduction time as determined by the polygraph is normal. Another point of interest in this case is the slow rate of the pacemaker under ordinary circumstances.

Volhard" writing on "heart-block" in 1909 described one case (Case 9) in which there was a somewhat similar paradoxical cardiac response to change in position. The patient lying flat had a pulse rate of 64 and no block; sitting up he had a pulse rate of 42 with a 2 to-1 block, his auricular rate actually being 84 ; on standing the pulse rate dropped to about 22 and hecame irregular, due to varying degrees of block from 2-to-1 to 5-to-1. Atropin in $V$ olhard's case did not affect the dissociation except to increase it slightly, due to the increase in rate of the auricles and the inability of the ventricles to keep pace.

Lutembacher $^{2}$ in 1919 described a case of "Orthostatic Bradycardia" due to "intermittence of conduction of the bundle of His." His case with an auricular rate of 60 showed no block, at 70 to 80 a 2-to-1 heart-block appeared, and with higher auricular rates 3-to-1 and even 4-to-1 heart-block was found. Thus there was an apparent paradoxical response to exercise here also. Atropin produced the same effect-ventricular slowing-as in Volhard's case.

\section{SUMMARY.}

A sase is reported showing a decrease in ventricular pulse rate with inspiration and exercise instead of the normal increase. The apparent paradox is due to the production of heart-block by increase of auricular rate plus depressed auriculo-ventrieular conduction.

REFERENCES.

1 Volhard, F.: Deutsch. Arch. f. klin. Med., 1909, xcvii, 348. 2 Lutembacher, R.: Arch. d. Mal. d. Coeur, 1919, xii, 145

\section{Soripty Rapart.}

PROCEEDINGS OF THE NEW ENGLAND BRANCH OF THE AMERICAN UROLOGICAL ASSOCIATION.

A MEETing was held at the Harvard Club of Boston on Tuesday evening, November 4, 1919, Dr. O'Neil presiding. Dr. E. G. Crabtree and 